Surfactant- and Reducer-Free Synthesis of Gold Nanoparticles in Aqueous Solutions

Toshio Sakai, ${ }^{a *}$ Hiroto Enomoto, ${ }^{\mathrm{b}}$ Kanjiro Torigoe, ${ }^{\mathrm{c}}$ Hideki Sakai $^{\mathrm{b}, \mathrm{c}}$ and Masahiko Abe ${ }^{\mathrm{b}, \mathrm{c}}$

\title{
Affiliation:
}

a International Young Researchers Empowerment Center, Shinshu University, 4-17-1 Wakasato, Nagano 380-8553, Japan

${ }^{\mathrm{b}}$ Department of Pure and Applied Chemistry, Faculty of Science and Technology, Tokyo University of Science, Noda, Chiba 278-8510, Japan.

${ }^{\mathrm{c}}$ Research Institute for Science and Technology, Tokyo University of Science, Noda, Chiba 278-8510, Japan

\section{*Mailing Address:}

International Young Researchers Empowerment Center, Shinshu University, 4-17-1

Wakasato, Nagano 380-8553, Japan

Phone : +81-26-269-5405

Fax : $+81-26-269-5424$

E-mail : tsakai@shinshu-u.ac.jp 


\begin{abstract}
We report here the surfactant- and reducer-free synthesis of gold nanoparticles from an aqueous hydrogen tetrachloroaurate (III) tetrahydrate $\left(\mathrm{HAuCl}_{4} \cdot 4 \mathrm{H}_{2} \mathrm{O}\right)$ solution using a high-frequency $(950 \mathrm{kHz})$ ultrasound (in the absence of any stabilizing, capping and reducing agents). In particular, size, shape and stability of gold nanoparticles prepared by the 950 $\mathrm{kHz}$ ultrasound irradiation (sonication) for $8 \mathrm{~min}$ in the surfactant-free aqueous solutions were examined in terms of $\mathrm{AuCl}_{4}{ }^{-}$concentration (in the range of 0.01-0.1 mM), additional salts $(\mathrm{NaCl}, \mathrm{HCl}$ and $\mathrm{NaOH})$ and temperature (in the range of $4-60{ }^{\circ} \mathrm{C}$ ). We found that higher $\mathrm{AuCl}_{4}{ }^{-}$concentration promoted particle growth (size increase) and plate formation. In addition, the plate formation was enhanced with the addition of $\mathrm{NaCl}$ or $\mathrm{HCl}$ (but not $\mathrm{NaOH}$ ). This is most likely due to the $\mathrm{AuCl}_{4}{ }^{-}$reduction on a certain crystal facets (e.g., (110) facets) caused by the adsorption of $\mathrm{Cl}^{-}$ions on specific crystal facets (e.g., (111) facets). Furthermore, we revealed that the temperature elevated above $50{ }^{\circ} \mathrm{C}$ led to the formation of spherical gold nanoparticles with the diameter of $20-60 \mathrm{~nm}$ from a $0.1 \mathrm{mM} \mathrm{AuCl}_{4}{ }^{-}$aqueous solution while triangular plates formed coexisting with spherical nanoparticles below $50{ }^{\circ} \mathrm{C}$.
\end{abstract}

Key words: gold nanoparticle; surfactant- and reducer-free synthesis; high-frequency ultrasound; sonochemical reduction; size- and shape-control 


\section{Introduction}

The great interest in metal nanoparticles is acquired due to their unique properties such as size- and shape-dependent optical, magnetic, electronic and catalytic properties. [1-25] An important and challenging task for metal nanoparticle synthesis is the development of simple and versatile methods for the preparation of nanoparticles in a size or shape-selected and -controlled manner.[1-25] In addition, synthetic strategy of metal nanoparticles in view of environmental and economical concerns (e.g., utilization of non-toxic chemicals, environmentally benign solvents, and renewable materials) are emerging issues that merit important consideration.[9]

Metal nanoparticle synthesis in solutions commonly requires utilization of surface-active agents (surfactants) and/or amphiphilic polymers as stabilizing agents and/or capping agents.[1-25] It is known that surfactants and/or amphiphilic polymers have critical roles for controlling the size, shape and stability of the dispersed particles.[1-25] Therefore, size-, shape- and stability-control of metal nanoparticles has been investigated in terms of molecular characteristics of surfactants and/or amphiphilic polymers, and the resulting interfacial properties.[1-25] However, surfactants and amphiphilic polymers would introduce complexities for understanding the mechanism on particle-size and -shape determination due to the incorporation of various factors such as adsorption of hydrophobic tail, hydrophilic head group and counter ions (in the case of ionic surfactants) on the surface of nuclei and/or small particles, and complexation of metal ions with surfactants and/or amphiphilic polymers.[12-25] Then we considered the surfactant- and reducer-free metal nanoparticle synthesis from metal ions in aqueous solutions (in the absence of any stabilizing, capping and reducing agents) to evaluate the mechanism on size-, shape- and stability-control of metal nanoparticles formed in solutions. Simplified system (surfactant- and reducer-free conditions) should manifest the essential mechanism on size-, shape- and stability-control of metal nanoparticles synthesized in aqueous solutions. At the same time, this should provide 
better insight on roles and utilization of stabilizing agents and/or capping agents (e.g., surfactants, amphiphilic polymers) for metal nanoparticle synthesis in solutions. Furthermore, the surfactant- and reducer-free metal nanoparticle synthesis matches with economical and/or environmental requirements since material use and operations (e.g., washing, waste treatment, recycling) are minimized.

In the present work, we investigated the surfactant- and reducer-free synthesis of gold nanoparticles from $\mathrm{AuCl}_{4}{ }^{-}$ion reduction in an aqueous hydrogen tetrachloroaurate (III) tetrahydrate $\left(\mathrm{HAuCl}_{4} \cdot 4 \mathrm{H}_{2} \mathrm{O}\right)$ solution using a high-frequency $(950 \mathrm{kHz})$ ultrasound. In particular, we examined the effects of $\mathrm{AuCl}_{4}{ }^{-}$concentration (in the range of 0.01-0.1 mM), additional salts $(\mathrm{NaCl}, \mathrm{HCl}$ and $\mathrm{NaOH})$ and temperature (in the range of $4-60{ }^{\circ} \mathrm{C}$ ) on the size, shape and stability of gold nanoparticles ultrasonically prepared in the surfactant-free aqueous solutions. We found that judicious selection of experimental conditions enabled to control the size, shape and stability of gold nanoparticles ultrasonically prepared even in the surfactant-free conditions. For example, size of the gold nanoparticles formed increased with $\mathrm{AuCl}_{4}{ }^{-}$concentration. The addition of $\mathrm{NaCl}$ or $\mathrm{HCl}$ into aqueous $\mathrm{AuCl}_{4}{ }^{-}$solutions promoted the plate formation. Furthermore, spherical gold nanoparticles with diameter in the range of 20-60 nm were selectively formed from a $0.1 \mathrm{mM} \mathrm{AuCl}_{4}^{-}$aqueous solution above $50{ }^{\circ} \mathrm{C}$ while triangular plates normally coexisted with spherical nanoparticles below 50 ${ }^{\circ} \mathrm{C}$.

\section{Experimental}

\subsection{Preparation of gold nanoparticles}

Gold nanoparticles were prepared through ultrasonic reduction of $\mathrm{AuCl}_{4}{ }^{-}$ions in an aqueous hydrogen tetrachloroaurate (III) tetrahydrate $\left(\mathrm{HAuCl}_{4} \cdot 4 \mathrm{H}_{2} \mathrm{O}\right.$, Wako) solution (in the concentration range of 0.01-0.1 mM) (following reaction scheme below) [5-7] in an ultrasonic bath (that enables to generate 28, 200 and $950 \mathrm{kHz}$ ultrasound) (Mitsui Electric Co. Ltd.) in 
the temperature range of $4-60{ }^{\circ} \mathrm{C}$. Ultra-pure water that we used in this experiment was purged by argon gas to promote the radical $\left(\mathrm{H}^{\cdot}\right.$ and $\left.\mathrm{OH} \cdot\right)$ formation from water.[26-29]

$$
\begin{aligned}
& 2 \mathrm{Au}^{\mathrm{III}} \mathrm{Cl}_{4}^{-}+\mathrm{H} \cdot \rightarrow 2 \mathrm{Au}^{\mathrm{II}} \mathrm{Cl}_{3}^{-}+\mathrm{Cl} \cdot+\mathrm{HCl} \\
& 2 \mathrm{Au}^{\mathrm{II}} \mathrm{Cl}_{3}^{-} \rightarrow \mathrm{Au}^{\mathrm{III}} \mathrm{Cl}_{4}^{-}+\mathrm{Au}^{\mathrm{I}} \mathrm{Cl}_{2}^{-} \\
& \mathrm{Au}^{\mathrm{I} C C_{2}^{-}}+\mathrm{H} \cdot \rightarrow \mathrm{Au}^{0}+\mathrm{HCl}+\mathrm{Cl}^{-} \\
& n \mathrm{Au}^{0} \rightarrow\left(\mathrm{Au}^{0}\right)_{n} \\
& \left(2 \mathrm{Au}^{\mathrm{I}}, \mathrm{Au}_{n}\right) \rightarrow\left(\mathrm{Au}^{\mathrm{II}}, \mathrm{Au}_{n+1}\right) \\
& \mathrm{Au}^{\mathrm{III}} \mathrm{Cl}_{4}^{-}+2 \mathrm{Au}^{0}+2 \mathrm{Cl}^{-} \leftrightarrow 3 \mathrm{Au}^{\mathrm{I}} \mathrm{Cl}_{2}^{-}
\end{aligned}
$$

In order to elucidate the contribution of chloride ions $\left(\mathrm{Cl}^{-}\right)$to the shape determination (crystal growth), gold nanoparticles were prepared from an aqueous hydrogen tetrachloroaurate (III) tetrahydrate with the addition of sodium chloride $(\mathrm{NaCl}$, Wako) or hydrogen chloride ( $\mathrm{HCl}$, Wako) at $25^{\circ} \mathrm{C}$. For comparison purpose, gold nanoparticles were prepared from an aqueous hydrogen tetrachloroaurate (III) tetrahydrate with the addition of sodium hydrogen oxide $\left(\mathrm{NaOH}\right.$, Wako) at $25{ }^{\circ} \mathrm{C}$.

\subsection{Characterization}

The reduction of $\mathrm{AuCl}_{4}{ }^{-}$was monitored by decrease of the $\mathrm{AuCl}_{4}{ }^{-}$concentration $\left(\left[\mathrm{Au}^{\mathrm{III}}\right]\right)$ in solutions with an inductively coupled plasma spectrometer (ICPS) (ICPS-7500, SHIMADZU). The formation of gold nanoparticels were confirmed by observing changes in the absorption spectra centered at $\sim 530 \mathrm{~nm}$ originating from surface plasmon resonance (SPR) of the gold nanoparticles[2] using a UV-visible spectrometer (U-3310, Hitachi High Technologies Co.). The size and shape of the obtained gold nanoparticles were observed by transmission electron microscopy (TEM) (H-7650, Hitachi High Technologies Co.) at an 
accelerating voltage of $120 \mathrm{kV}$ under a low electron dose. The size distributions of the gold nanoparticles synthesized were obtained by measuring the diameter of more than 500 particles viewed in the micrographs.

\subsection{Optimization of ultrasound frequency and irradiation time}

Frequency and irradiation time of ultrasound that we used in this experiment for $\mathrm{AuCl}_{4}{ }^{-}$reduction and gold nanoparticle formation were optimized before we discuss the effects of $\mathrm{AuCl}_{4}{ }^{-}$concentration, salt addition and temperature on the size, shape and stability of gold nanoparticles. We first checked the effects of ultrasound frequencies $(28,200$ and $950 \mathrm{kHz})$ on the $\mathrm{AuCl}_{4}{ }^{-}$reduction, and the resulting gold nanoparticle formation at $25{ }^{\circ} \mathrm{C}$. Concentration of $\mathrm{AuCl}_{4}^{-}\left(\left[\mathrm{Au}^{\mathrm{III}}\right]\right)$ in solutions measured with ICPS decreased as a function of ultrasound irradiation time (sonication time) (see Figure 1). This indicates that $\mathrm{AuCl}_{4}{ }^{-}$ions were reduced by sonication (following reaction scheme above). Concentration of $\mathrm{AuCl}_{4}{ }^{-}$ ions in the bulk solution decreased linearly and became zero at $\sim 6 \mathrm{~min}$ in the case of the 200 $\mathrm{kHz}$ and $950 \mathrm{kHz}$ sonication (see Figure 1). On the other hand, the decrease of $\mathrm{AuCl}_{4}{ }^{-}$ concentration was not significant for $28 \mathrm{kHz}$ sonication (see Figure 1). These indicate that higher-frequency ultrasound is more effective on $\mathrm{AuCl}_{4}{ }^{-}$reduction than lower-frequency ultrasound. This is consistent with the amount of radicals generated by sonication. The amount of radicals estimated from the amount of Fe(III) ions $\left(\varepsilon=2194 \mathrm{M}^{-1} \mathrm{~cm}^{-1}, \lambda=304\right.$ $\mathrm{nm}$ ) formed from $\mathrm{Fe}(\mathrm{II})$ oxidation by $\mathrm{H}_{2} \mathrm{O}_{2}$ and $\mathrm{OH} \cdot[30-32]$ increased with the order of $28<<$ $200 \approx 950 \mathrm{kHz}$ (the result is not reported here). Consequently, absorption bands centered at $\sim 530 \mathrm{~nm}$ originating from SPR of gold nanoparticles were observed in the case of 200 and $950 \mathrm{kHz}$ sonication while no noticeable peak for $28 \mathrm{kHz}$ sonication was observed even in the sonication for $10 \mathrm{~min}$ (see Figure 2). Thus, we mainly used the $950 \mathrm{kHz}$ ultrasound for $\mathrm{AuCl}_{4}{ }^{-}$reduction and gold nanoparticle formation in this work. Note that particles prepared using the $950 \mathrm{kHz}$ ultrasound were assigned as gold from X-ray diffraction pattern (the result 
is not reported here).

Having established the frequency $(950 \mathrm{kHz})$ of ultrasound that we used in this work, we next optimized sonication time. We have already realized that reduction of $0.1 \mathrm{mM}$ $\mathrm{AuCl}_{4}{ }^{-}$completed at $\sim 6$ min with $950 \mathrm{kHz}$ sonication (from ICPS measurements) (see Figure 1). In order to determine the sonication time for $\mathrm{AuCl}_{4}{ }^{-}$reduction and gold nanoparticle formation in this work, absorption spectra centered at $\sim 530 \mathrm{~nm}$ originating from SPR of gold nanoparticles were also monitored as a function of sonication time. The absorbance plotted in Figure 3 as a function of sonication time increased up to $7 \mathrm{~min}$, and became plateau (or slightly decreased) after that. These indicate that sonication longer than $7 \mathrm{~min}$ is required for reduction of $0.1 \mathrm{mM} \mathrm{AuCl}_{4}{ }^{-}$ions and gold nanoparticle formation in the $950 \mathrm{kHz}$ ultrasound. TEM observation revealed that sonication over $7 \mathrm{~min}$ (e.g., 8 and $10 \mathrm{~min}$ ) resulted in the formation of individual gold nanoparticles with the diameter of $\sim 30 \mathrm{~nm}$ (that coexist with triangular and hexagonal plates) through the reduction of $0.1 \mathrm{mM} \mathrm{AuCl}_{4}{ }^{-}$while shorter sonication than $7 \mathrm{~min}$ (e.g., 1 and $5 \mathrm{~min}$ ) produced aggregates of tiny particles (see

Figure 4). So we adopted sonication time for $8 \mathrm{~min}$ (in the case of $950 \mathrm{kHz}$ ultrasound) for $\mathrm{AuCl}_{4}{ }^{-}$reduction and gold nanoparticle formation in this work.

\section{Results and Discussion}

3.1 Effect of $\mathrm{AuCl}_{4}{ }^{-}$concentration on particle size, shape and stability

Size and shape of metal nanoparticles are typically determined by competition between nucleation (metal ion reduction in bulk) and growth (metal ion reduction on nuclei) processes. Namely, if metal ion reduction in the bulk solution were more dominant than on the nuclei and/or small particles, new particle formation (number increase) would be more significant than particle growth (size increase). Alternately, if metal ion reduction occurred on the nuclei and/or small particles more dominantly than in the bulk solution, then particle growth (size increase) would be more significant. Then we examined the effects of $\mathrm{AuCl}_{4}{ }^{-}$ 
concentration (in the range of $0.01-0.1 \mathrm{mM}$ ) on the size and shape of gold nanoparticles prepared using $950 \mathrm{kHz}$ ultrasound to understand the nucleation and growth processes of gold nanoparticles formed by $950 \mathrm{kHz}$ sonication. In the case of a $0.01 \mathrm{mM} \mathrm{AuCl}_{4}{ }^{-}$aqueous solution, spherical gold nanoparticles with average diameter of $8 \mathrm{~nm}$ were formed after 950 $\mathrm{kHz}$ sonication for $8 \mathrm{~min}$ at $25^{\circ} \mathrm{C}$ (see Figure 5). Gold nanoparticles synthesized from 0.05 , 0.08 and $0.1 \mathrm{mM} \mathrm{AuCl}_{4}{ }^{-}$aqueous solution were spheres with average diameter of 14,21 and $26 \mathrm{~nm}$, respectively, that coexist with triangular and hexagonal plates with the side of 20-100 nm (see Figure 5). The size increase of gold nanoparticles formed with higher $\mathrm{AuCl}_{4}{ }^{-}$ concentrations indicates that $\mathrm{AuCl}_{4}{ }^{-}$reduction occurs preferably on the nuclei and/or small particles rather than in bulk solutions.

We here checked stability of the gold nanoparticles thus formed. Size and shape of the gold nanoparticles formed from 0.01 and $0.05 \mathrm{mM} \mathrm{AuCl}_{4}{ }^{-}$aqueous solutions remained unchanged over 30 days (see Figure 6). On the other hand, gold nanoparticles synthesized from 0.08 and $0.1 \mathrm{mM} \mathrm{AuCl}_{4}{ }^{-}$aqueous solutions merged into larger ones with elapsed time (see Figure 6). This is most likely due to the remaining of reactable components such as $\mathrm{AuCl}_{2}{ }^{-}$on the particle surface.[3]

\subsection{Effect of chloride ions on particle shape determination}

We now realized that spherical gold nanoparticles and triangular and/or hexagonal plates were typically formed in our system. In particular, triangular and/or hexagonal plates were formed from higher $\mathrm{AuCl}_{4}{ }^{-}$concentration solutions. This suggests that $\mathrm{AuCl}_{4}{ }^{-}$ reduction occurs on a certain crystal facets. We considered that the formation of triangular and/or hexagonal plates is related to the adsorption of chloride ions $\left(\mathrm{Cl}^{-}\right)$(produced during $\mathrm{AuCl}_{4}{ }^{-}$reduction) onto specific crystal facets because $\mathrm{Cl}^{-}$ions prefer to adsorb on gold surface.[33] So we here examined the gold nanoparticle synthesis with the addition of sodium chloride $(\mathrm{NaCl})$. Indeed, formation of triangular and/or hexagonal plates was 
promoted with the addition of $\mathrm{NaCl}$, and size of the plate increased with $\mathrm{NaCl}$ concentration increase (see Figure 7). This indicates that $\mathrm{NaCl}$ enhanced the plate formation. For comparison purpose, we tested the effect of sodium hydrogen oxide $(\mathrm{NaOH})$ on the shape (growth) of gold nanoparticles formed. No remarkable difference on particle-size and -shape between absence $(\mathrm{pH}=3.6)$ and presence of $\mathrm{NaOH}(\mathrm{pH}=5.0$ and 7.0) were observed by TEM (see Figure 8). These results suggest that $\mathrm{Cl}^{-}$ions contribute to the determination of particle shape, that is, determination of $\mathrm{AuCl}_{4}{ }^{-}$reduction site. This also suggests the adsorption of $\mathrm{Cl}^{-}$ions onto specific crystal facets. Affinity of $\mathrm{Cl}^{-}$ions to gold surface is stronger than that of $\mathrm{OH}^{-}$ions, [33] so $\mathrm{Cl}^{-}$ions should affect strongly crystal growth and the resulting particle shape compared to $\mathrm{OH}^{-}$ions. Contribution of $\mathrm{Cl}^{-}$ions to plate formation (crystal growth) was also confirmed with the addition of hydrogen chloride $(\mathrm{HCl})(\mathrm{pH}=3.0)$ (see Figure 8). A similar result on plate formation promoted with the addition of a small amount of halide ion (especially, iodide ion) in a growth solution has been reported in the presence of cetyltrimethylammonium bromide (CTAB).[34]

\subsection{Effect of temperature on particle size and shape}

Finally, let us examine how temperature affects the size and shape of gold nanoparticles ultrasonically prepared in the absence of any stabilizing and capping agents. Since bulk solution temperature affects radial generation by sonication, [31, 32] temperature should enable to control the competition between nucleation (metal ion reduction in bulk solution) and growth (metal ion reduction on nuclei) processes, and the resulting size and shape of metal nanoparticles. Then, we prepared gold nanoparticles from the reduction of $0.1 \mathrm{mM} \mathrm{AuCl}_{4}{ }^{-}$by the $950 \mathrm{kHz}$ sonication at different temperatures in the range of $4-60{ }^{\circ} \mathrm{C}$. In the case of temperature range of $4-40{ }^{\circ} \mathrm{C}$, triangular and hexagonal plates with the side of 20-200 nm typically formed coexisting with spherical gold nanoparticles with diameter of 20-60 nm (see Figure 9). The triangular and hexagonal plates became smaller (the side of 
20-60 nm) at $50{ }^{\circ} \mathrm{C}$. Further elevation of temperature up to $60{ }^{\circ} \mathrm{C}$ led to the selective-formation of spherical gold nanoparticles with the diameter of 20-60 $\mathrm{nm}$. The dramatic change with elevated temperature from 4 to $60{ }^{\circ} \mathrm{C}$ was also confirmed by absorption spectra. Two absorption bands centered at $\sim 530 \mathrm{~nm}$ and $\sim 750 \mathrm{~nm}$ were observed in the case of gold nanoparticle dispersions prepared in the temperature range of $4-40{ }^{\circ} \mathrm{C}$ (see Figure 10). This indicates that spherical nanoparticles and anisotropic particles such as plate-like particles coexist in the same solution.[11, 22] On the other hand, an absorption band centered at $\sim 530 \mathrm{~nm}$ was observed in the case of gold nanoparticle dispersions prepared at 50 and $60{ }^{\circ} \mathrm{C}$ (see Figure 10), indicating the formation of spherical nanoparticles.[11, 22] These obviously indicate that bulk solution temperature is a critical role on size and shape control of gold nanoparticles.

Typically, smaller particles are formed if nucleation process is more dominant than growth process. Alternatively, larger particles are formed if growth process is more significant than nucleation process. However, this concept cannot explain the results obtained in our experiments because higher bulk solution temperature prevents the genration of radicals to reduce $\mathrm{AuCl}_{4}^{-} \cdot[31,32,35]$ Namely, fewer radicals produced at higher bulk solution temperature mean lower number of nucleation events. Indeed, in our experimental setup, the amount of radicals estimated from the concentration of $\mathrm{Fe}(\mathrm{III})$ ions $\left(\varepsilon=2194 \mathrm{M}^{-1}\right.$ $\mathrm{cm}^{-1}, \lambda=304 \mathrm{~nm}$ ) formed from $\mathrm{Fe}(\mathrm{II})$ oxidation by $\mathrm{H}_{2} \mathrm{O}_{2}$ and $\mathrm{OH} \cdot[30-32]$ plotted as a function of temperature increased in the range of $4-40{ }^{\circ} \mathrm{C}$, and decreased drastically at 50 and $60{ }^{\circ} \mathrm{C}$ (the result is not reported here). These suggest that formation of the spherical gold nanoparticles at 50 and $60{ }^{\circ} \mathrm{C}$ is not attributed to the nucleation caused by radical generation. Formation of the spherical gold nanoaprticles at 50 and $60{ }^{\circ} \mathrm{C}$ is most likely due to the deformation and/or dissolution of gold plates induced by the elevated bulk solution temperature because the gold plates formed in our experiments are not stable. Disappearance of gold plates observed at 30 days after preparation (see Figures 5 and 6) 
indicates instability of the gold plates initially formed.

\section{Conclusions}

We addressed in this paper the surfactant- and reducer-free synthesis of gold nanoparticles through sonochemical reduction of $\mathrm{AuCl}_{4}{ }^{-}$ions in aqueous solutions to elucidate the mechanism on size-, shape- and stability-determination of gold nanoparticles in solutions. Frequency and irradiation time of ultrasound that we use were first optimized for $\mathrm{AuCl}_{4}{ }^{-}$reduction and gold nanoparticle formation. And following, size, shape and stability of gold nanoparticles synthesized using a high-frequency ultrasound $(950 \mathrm{kHz}$ ) were examined in terms of $\mathrm{AuCl}_{4}{ }^{-}$ion concentration, salt $(\mathrm{NaCl}, \mathrm{NaOH}$ and $\mathrm{HCl})$ addition and temperature in the absence of any stabilizing, capping and reducing agents. We found that size of gold nanoparticles formed increased with $\mathrm{AuCl}_{4}{ }^{-}$concentration increase. In addition, plate formation was promoted with $\mathrm{AuCl}_{4}{ }^{-}$concentration increase. These indicate that $\mathrm{AuCl}_{4}{ }^{-}$reduction occurs preferably on specific crystal facets of the nuclei and/or small particles. In particular, the plate formation and plate-size increase were enhanced in the presence of chloride ions $\left(\mathrm{Cl}^{-}\right)$(with the addition of $\mathrm{NaCl}$ or $\mathrm{HCl}$ ). These suggest that $\mathrm{AuCl}_{4}{ }^{-}$reduction occurs on a certain crystal facets of the nuclei and/or small particles due to the adsorption of $\mathrm{Cl}^{-}$ions onto specific crystal facets. Temperature also affected size and shape of gold nanoparticles formed even in the absence of any stabilizing agents and capping agents. Especially, temperature elevated above $50{ }^{\circ} \mathrm{C}$ led to the selective-formation of spherical nanoparticles. These findings that we reported should provide better insight on control mechanism of size and shape of metal nanoparticles, in addition to the roles of stabilizing agents and capping agents on size and shape determination. Note here again that the surfactant- and reducer-free metal nanoparticle synthesis matches with economical and/or environmental requirements due to the minimization of material use and operations. We believe that these findings and concepts on surfactant- and reducer-free metal nanoparticle 
synthesis will lead to further development on nanotechnology field.

\section{Acknowledgments}

We are grateful to Shinkou Kagaku Co. Ltd. for support of this research. 


\section{References}

[1] M. P. Pileni, Nanosized Particles Made in Colloidal Assemblies, Langmuir 13 (1997) 3266-3276.

[2] S. Link, M. A. El-Sayed, Spectral Properties and Relaxation Dynamics of Surface Plasmon Electronic Oscillations in Gold and Silver Nanodots and Nanorods, J. Phys. Chem. B 103 (1999) 8410-8426.

[3] G. Tsutsui, S. Huang, H. Sakaue, S. Shingubara, T. Takayuki, Well-Size-Controlled Colloidal Gold Nanoparticles Dispersed in Organic Solvents, Jpn. J. Appl. Phys. 40 (2001) 346-349.

[4] M. Mandal, S. K. Ghosh, S. Kundu, K. Esumi, T. Pal, UV Photoactivation for Size and Shape Controlled Synthesis and Coalescence of Gold Nanoparticles in Micelles, Langmuir 18 (2002) 7792-7797.

[5] K. Kurihara, J. Kizling, P. Stenius, J. H. Fendler, Laser and Pulse Radiolytically Induced Colloidal Gold Formation in Water and in Water-in-Oil Microemulsions, J. Am. Chem. Soc. 105 (1983) 2574-2579.

[6] R. A. Caruso, M. Ashokkumar, F. Grieser, Sonochemical Formation of Gold Sols, Langmuir 18 (2002) 7831-7836.

[7] J. Rodriguez-Fernandez, J. Perez-Juste, P. Mulvaney, L. M. Liz-Marzan, Spatially-Directed Oxidation of Gold Nanoparticles by Au(III)-CTAB Complexes, J. Phys. Chem. B 109 (2005) 14257-14261.

[8] F. Chen, G.-Q. Xu, T. S. A. Hor, Preparation and Assembly of Colloidal Gold Nanoparticles in CTAB-Stabilized Reverse Microemulsion, Mater. Lett. 57 (2003) 3282-3286.

[9] P. Raveendran, J. Fu, S. L. Wallen, Completely "Green” Synthesis and Stabilization of Metal Nanoparticles, J. Am. Chem. Soc. 125 (2003) 13940-13941. 
[10] M.-C. Daniel, D. Autruc, Gold Nanoparticles: Assembly, Supramolecular Chemistry, Quantum-Size-Related Properties, and Applications toward Biology, Catalysis, and Nanotechnology, Chem. Rev. 104 (2004) 293-346.

[11] C. J. Orendorff, T. K. Sau, C. J. Murphy, Shape-Dependent Plasmon-Resonant Gold Nanoparticles, Small 2 (2006) 636-639.

[12] N. R. Jana, L. Gearheart, C. J. Murphy, Wet Chemical Synthesis of Silver Nanorods and Nanowires of Controllable Aspect Ratio, Chem. Commun. (2001) 617-618.

[13] N. R. Jana, Nanorod Shape Separation Using Surfactant Assisted Self-Assembly, Chem. Commun. (2003) 1950-1951.

[14] B. Nikoobakht, M. A. El-Sayed, Evidence for Bilayer Assembly of Cationic Surfactants on the Surface of Gold Nanorods, Langmuir 17 (2001) 6368-6374.

[15] M. Jaschke, H.-J. Butt, H. E. Gaub, S. Manne, Surfactant Aggregates at a Metal Surface, Langmuir 13 (1997) 1381-1384.

[16] J. Gao, C. M. Bender, C. J. Murphy, Dependence of the Gold Nanorod Aspect Ratio on the Nature of the Directing Surfactant in Aqueous Solution, Langmuir 19 (2003) 9065-9070.

[17] T. Sakai, P. Alexandridis, Single-Step Synthesis and Stabilization of Metal Nanoparticles in Aqueous Pluronic Block Copolymer Solutions at Ambient Temperature, Langmuir 20 (2004) 8426-8430.

[18] T. Sakai, P. Alexandridis, Mechanism of Metal Ion Reduction, Nanoparticle Growth and Size Control in Aqueous Amphiphilic Block Copolymer Solutions at Ambient Conditions, J. Phys. Chem. B 109 (2005) 7766-7777.

[19] C. Ni, P. A. Hassan, E. W. Kaler, Structural Characteristics and Growth of Pentagonal Silver Nanorods Prepared by a Surfactant Method, Langmuir 21 (2005) 3334-3337.

[20] T. K. Sau, C. J. Murphy, Self-Assembly Patterns Formed upon Solvent Evaporation of Aqueous Cetyltrimethylammonium Bromide-Coated Gold Nanoparticles of Various 
Shapes, Langmuir 21 (2005) 2923-2929.

[21] L. Gou, C. J. Murphy, Fine-Tuning the Shape of Gold Nanorods, Chem. Mater. 17 (2005) 3668-3672.

[22] C. J. Murphy, T. K. San, A. M. Gole, C. J. Orendorff, J. X. Gao, L. Gou, S. E. Hunyadi, T. Li, Anisotropic Metal Nanoparticles: Synthesis, Assembly, and Optical Applications, J. Phys. Chem. B 109 (2005) 13857-13870.

[23] Z. Kiraly, G. H. Findenegg, A. Mastalir, Adsorption of Dodecyltrimethylammonium Bromide and Sodium Bromide on Gold Studied by Liquid Chromatography and Flow Adsorption Microcalorimetry, Langmuir 22 (2006) 3207-3213.

[24] H. Kawasaki, K. Nishimura, R. Arakawa, Influence of the Counterions of Cetyltrimethylammonium Salts on the Surfactant Adsorption onto Gold Surfaces and the Formation of Gold Nanoparticles, J. Phys. Chem. C 111 (2007) 2683-2690.

[25] T. K. Sau, C. J. Murphy, Role of Ions in the Colloidal Synthesis of Gold Nanowires, PHILOSOPHICAL MAGAZINE 87 (2007) 2143-2158.

[26] K. Makino, M. M. Mossoba, P. Riesz, Chemical Effects of Ultrasound on Aqueous Solutions. Evidence for Hydroxyl and Hydrogen Free Radicals (.cntdot.OH and .cntdot.H) by Spin Trapping, J. Am. Chem. Soc. 104 (1982) 3537-3539.

[27] Y. T. Didenko, W. B. McNamara III, K. S. Suslick, Effect of Noble Gases on Sonoluminescence Temperatures during Multibubble Cavitation, Phys. Rev. Lett. 84 (2000) 777-780.

[28] K. Yasui, Single-Bubble Sonoluminescence from Noble Gases, Phys. Rev. E 63 (2001) 1-4.

[29] K. Yasui, T. Tuziuti, M. Sivakumar, Y. Iida, Theoretical Study of Single-Bubble Sonochemistry, J. Chem. Phys. 122 (2005) 1-12.

[30] Y. Nagata, Y. Mizukoshi, K. Okitsu, Y. Maeda, Sonochemical Formation of Gold Particles in Aaqueous Solution, Radiation Research 146 (1996) 333-338. 
[31] K. Okitsu, A. Yue, S. Tanabe, H. Matsumoto, Y. Yobiko, Y. Yoo, Sonolytic Control of Rate of Gold(III) Reduction and Size of Formed Gold Nanoparticles: Relation between Reduction Rates and Sizes of Formed Nanoparticles, Bull. Chem. Soc. Jpn. 75 (2002) 2289-2296.

[32] K. Okitsu, M. Ashokkumar, F. Grieser, Sonochemical Synthesis of Gold Nanoparticles: Effects of Ultrasound Frequency, J. Phys. Chem. B 109 (2005) 20673-20675.

[33] W.-k. Paik, M. A. Genshaw, J. O'M. Bockris, The Adsorption of Anions at the Solid-Solution Interface. An Elliposometric Study, J. Phys. Chem. 74 (1970) 42664275 .

[34] T. H. Ha, H. J. Koo, B. H. Chung, Shape-Controlled Syntheses of Gold Nanoprisms and Nanorods Influenced by Specific Adsorption of Halide Ions, J. Phys. Chem. C 111 (2007) 1123-1130.

[35] E. Ciawi, J. Rae, M. Ashokkumar, F. Grieser, Determination of Temperatures within Acoustically Generated Bubbles in Aqueous Solutions at Different Ultrasound Frequencies, J. Phys. Chem.B 110 (2006) 13656-13660. 


\section{Figure captions}

Figure 1. Concentration of $\mathrm{AuCl}_{4}^{-}\left(\left[\mathrm{Au}^{\mathrm{III}}\right]\right)$ monitored with ICPS as a function of sonication time, using different frequency ultrasounds; $28(\square), 200(\bigcirc)$ and $950 \mathrm{kHz}(\bigcirc)$ at $25{ }^{\circ} \mathrm{C}$. Concentration of $\mathrm{AuCl}_{4}{ }^{-}$at reaction initiation is $0.1 \mathrm{mM}$.

Figure 2. Absorption spectra originating from SPR of gold nanoparticles recorded after sonication of an aqueous $0.1 \mathrm{mM} \mathrm{AuCl}_{4}{ }^{-}$solution for 10 min using different frequency ultrasounds, 28 (solid line), 200 (dashed line) and $950 \mathrm{kHz}$ (solid line) at $25^{\circ} \mathrm{C}$.

Figure 3. (Upper panel) Absorption spectra originating from SPR of gold nanoparticles formed from an aqueous $0.1 \mathrm{mM} \mathrm{AuCl}_{4}{ }^{-}$solution using $950 \mathrm{kHz}$ ultrasound at various sonication times; (line a) 1, (line b) 2, (line c) 4, (line d) 6 and (line e) $7 \mathrm{~min}$ at $25{ }^{\circ} \mathrm{C}$. (Bottom panel) Absorbances (Abs.Max) of SPR centered at $\sim 530 \mathrm{~nm}$ plotted as a function of sonication time.

Figure 4. TEM images of gold nanoparticles formed from reduction of $0.1 \mathrm{mM} \mathrm{AuCl}_{4}{ }^{-}$with $950 \mathrm{kHz}$ ultrasounds at various sonication times; $1,5,8$ and 10 min at $25^{\circ} \mathrm{C}$.

Figure 5. TEM images and size distributions of gold nanoparticles observed immediately after preparation of gold nanoparticles from aqueous $0.01,0.05,0.08$ and $0.1 \mathrm{mM} \mathrm{AuCl}_{4}^{-}$ solutions by $950 \mathrm{kHz}$ sonication for $8 \mathrm{~min}$ at $25^{\circ} \mathrm{C}$.

Figure 6. TEM images of gold nanoparticles observed at 30 days after preparation of gold nanoparticles from aqueous $0.01,0.05,0.08$ and $0.1 \mathrm{mM} \mathrm{AuCl}_{4}{ }^{-}$solutions by $950 \mathrm{kHz}$ sonication for 8 min at $25{ }^{\circ} \mathrm{C}$. 
Figure 7. TEM images of gold nanoparticles formed from aqueous $0.1 \mathrm{mM} \mathrm{AuCl}_{4}{ }^{-}$solutions by $950 \mathrm{kHz}$ sonication for 8 min with the addition of $\mathrm{NaCl}(0,0.01,0.1,1$ and $10 \mathrm{mM})$ at 25 ${ }^{\circ} \mathrm{C}$.

Figure 8. TEM images of gold nanoparticles formed from aqueous $0.1 \mathrm{mM} \mathrm{AuCl}_{4}{ }^{-}$solutions by $950 \mathrm{kHz}$ sonication for $8 \mathrm{~min}$ with the addition of $\mathrm{HCl}(\mathrm{pH}=3)$, and $\mathrm{NaOH}(\mathrm{pH}=5$ and 7) at $25{ }^{\circ} \mathrm{C}$. The aqueous $0.1 \mathrm{mM} \mathrm{AuCl}_{4}{ }^{-}$solution that we used is $\mathrm{pH}=3.6$.

Figure 9. TEM images of gold nanoparticles formed from aqueous $0.1 \mathrm{mM} \mathrm{AuCl}_{4}{ }^{-}$solutions by $950 \mathrm{kHz}$ sonication for $8 \mathrm{~min}$ at $4,10,20,30,40,50$ and $60{ }^{\circ} \mathrm{C}$.

Figure 10. (Upper panel) Absorption spectra originating from SPR of gold nanoparticles formed from aqueous $0.1 \mathrm{mM} \mathrm{AuCl}_{4}{ }^{-}$solutions by $950 \mathrm{kHz}$ sonication for 8 min at (line a) 4, (line b) 10, (line c) 20, (line d) 30, (line e) 40, (line f) 50 and (line g) $60{ }^{\circ} \mathrm{C} . \quad$ (Bottom panel) Absorbances (Abs.Max) of SPR centered at $\sim 530 \mathrm{~nm}(\bigcirc)$ and at 700-800 $\mathrm{nm}(\bigcirc)$ plotted as a function of temperature. 
Figure 1. Sakai et al.

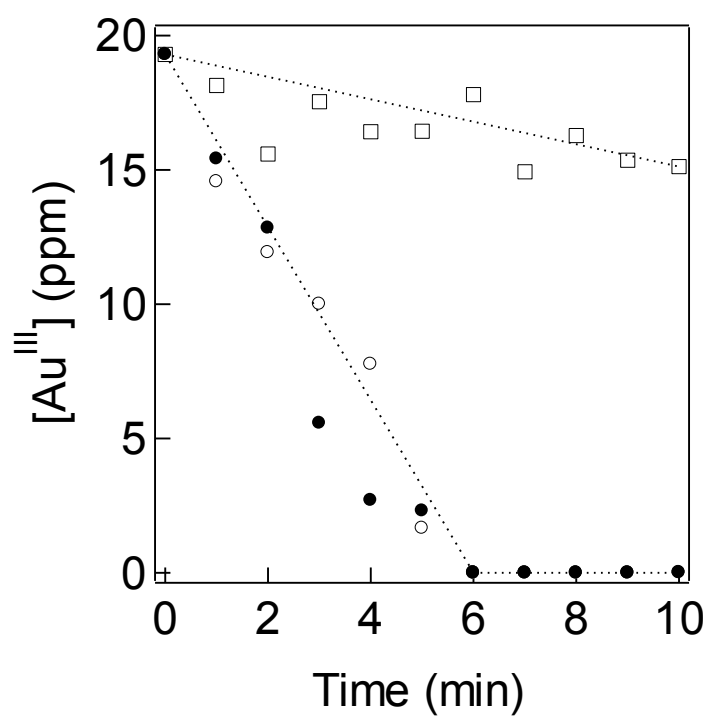


Figure 2. Sakai et al.

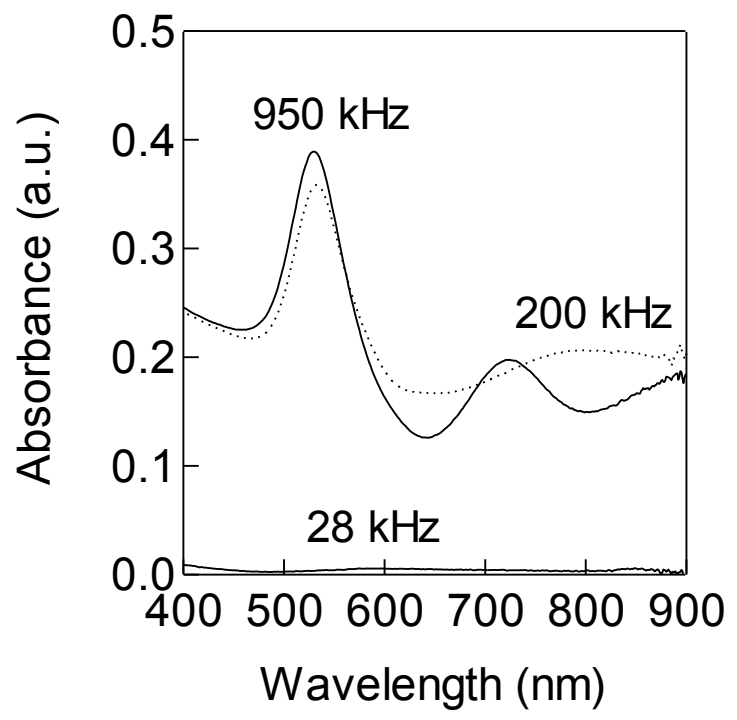


Figure 3. Sakai et al.
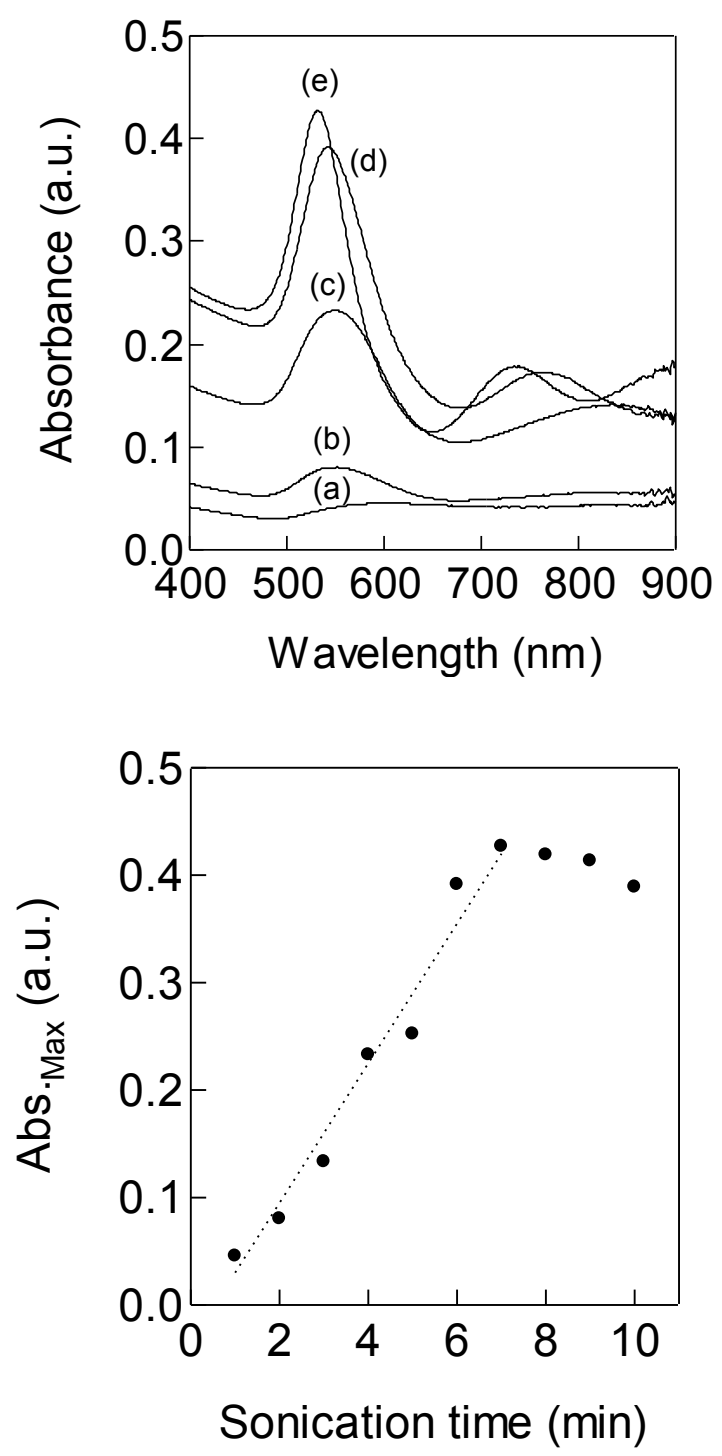
Figure 4. Sakai et al.
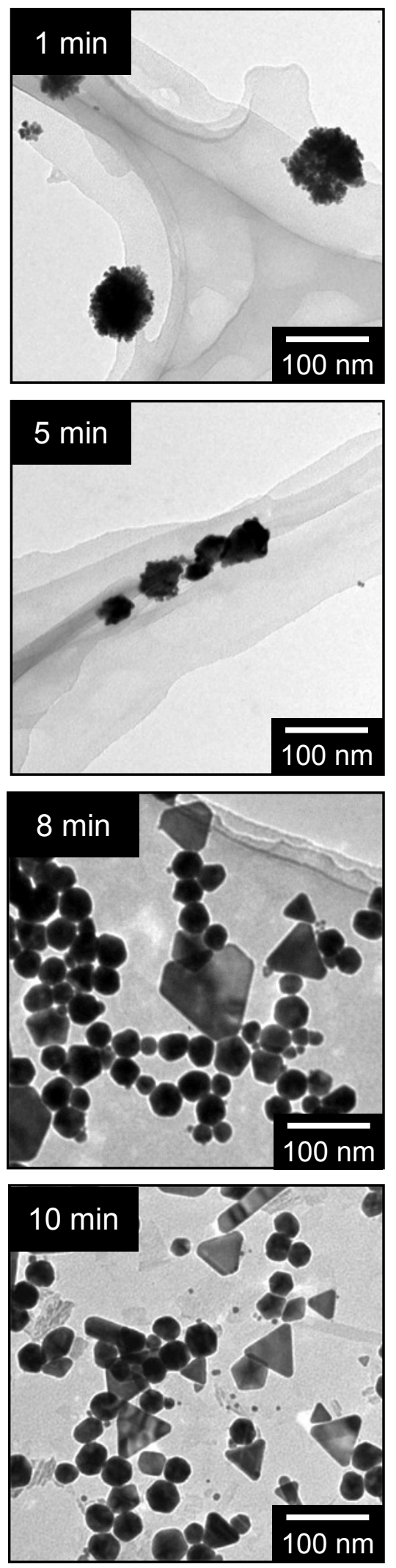
Figure 5. Sakai et al.
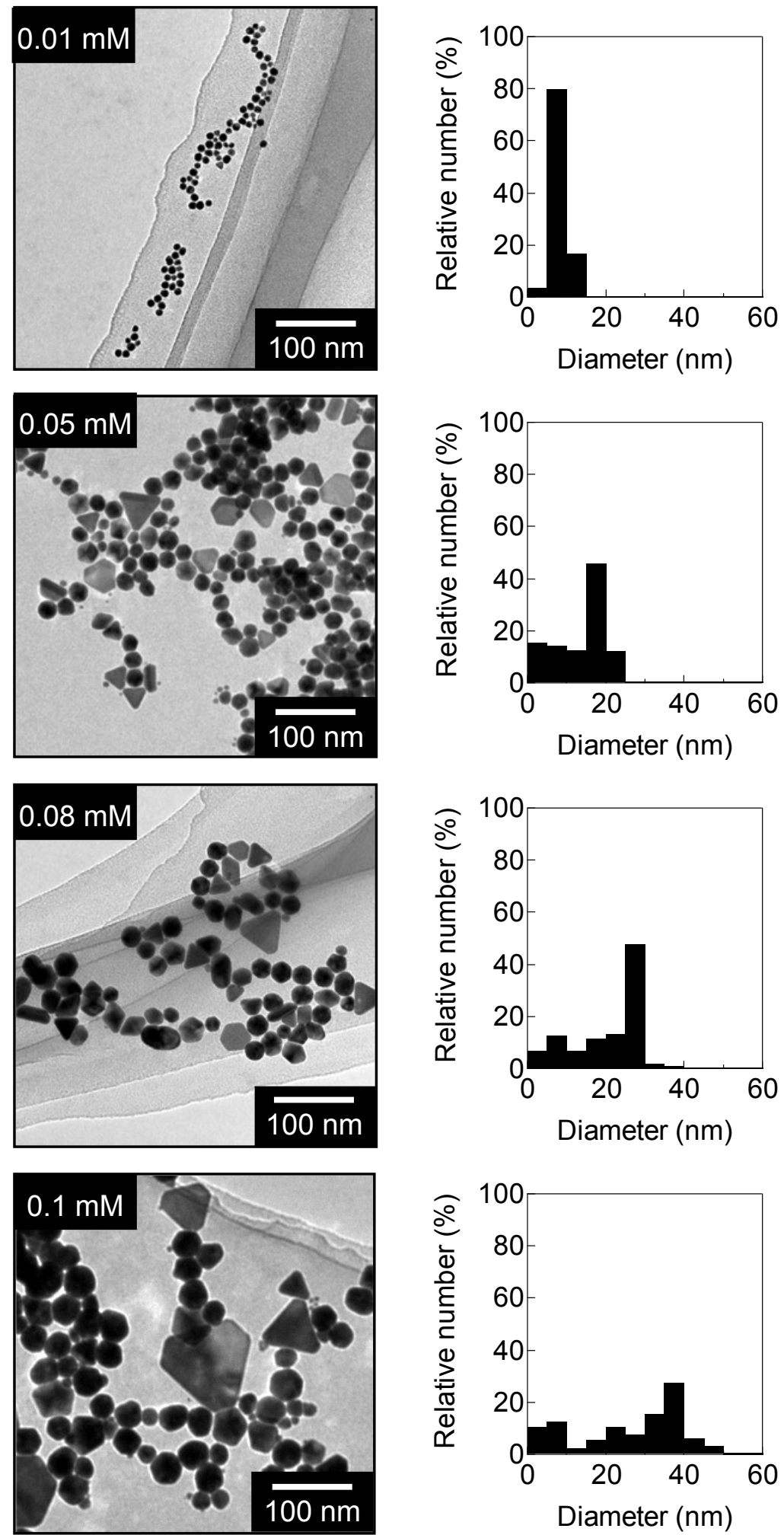
Figure 6. Sakai et al.
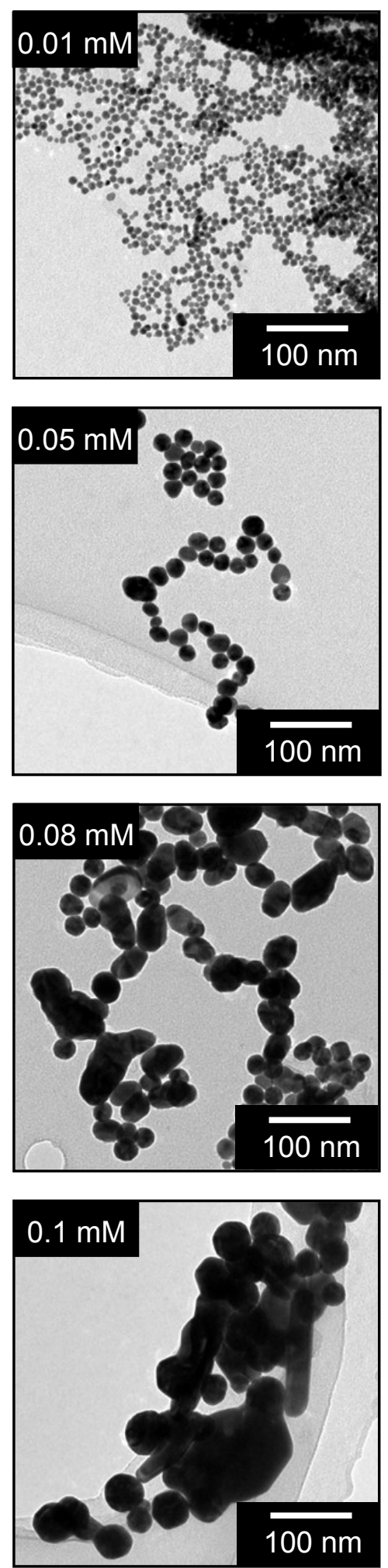
Figure 7. Sakai et al.
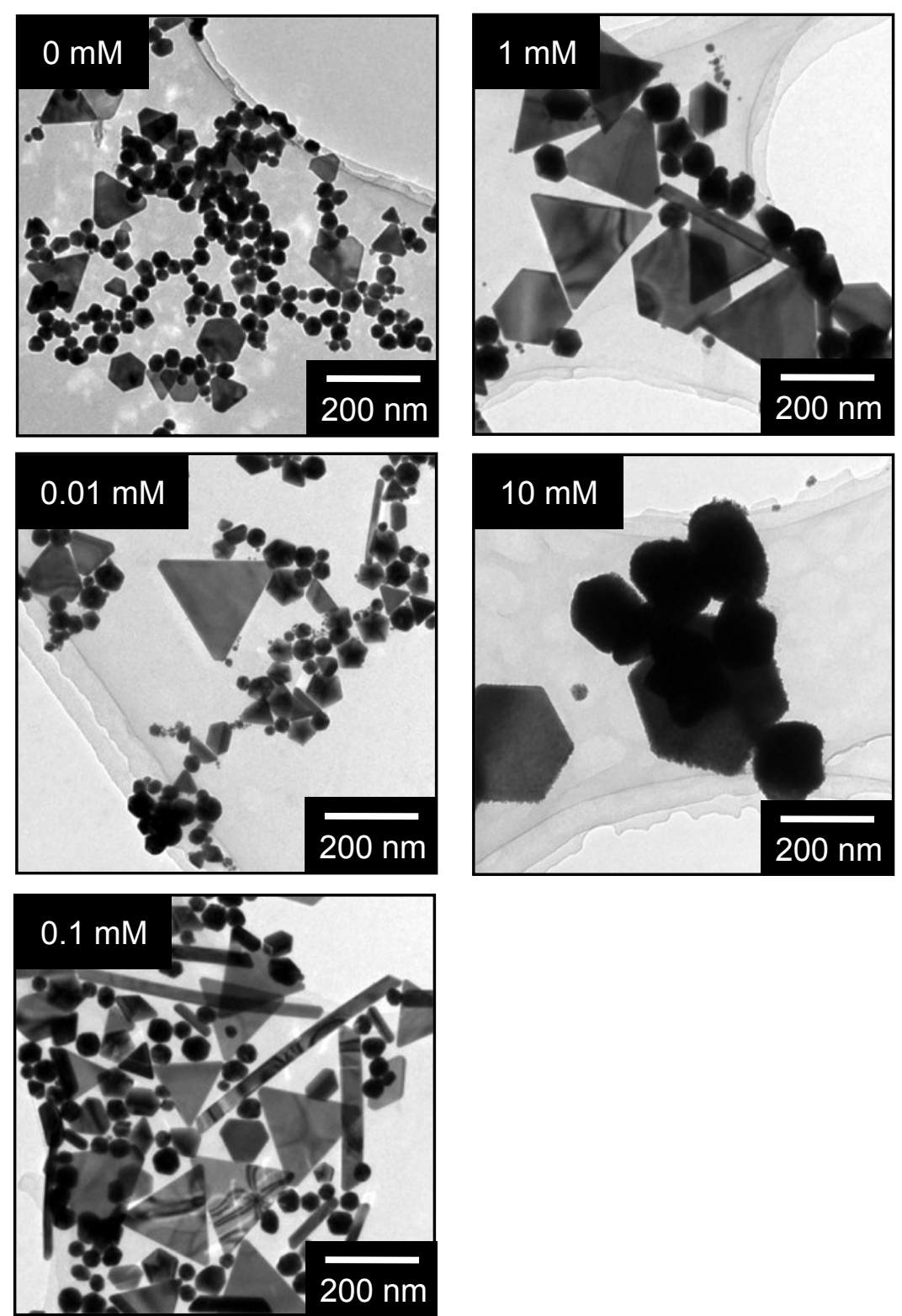
Figure 8. Sakai et al.
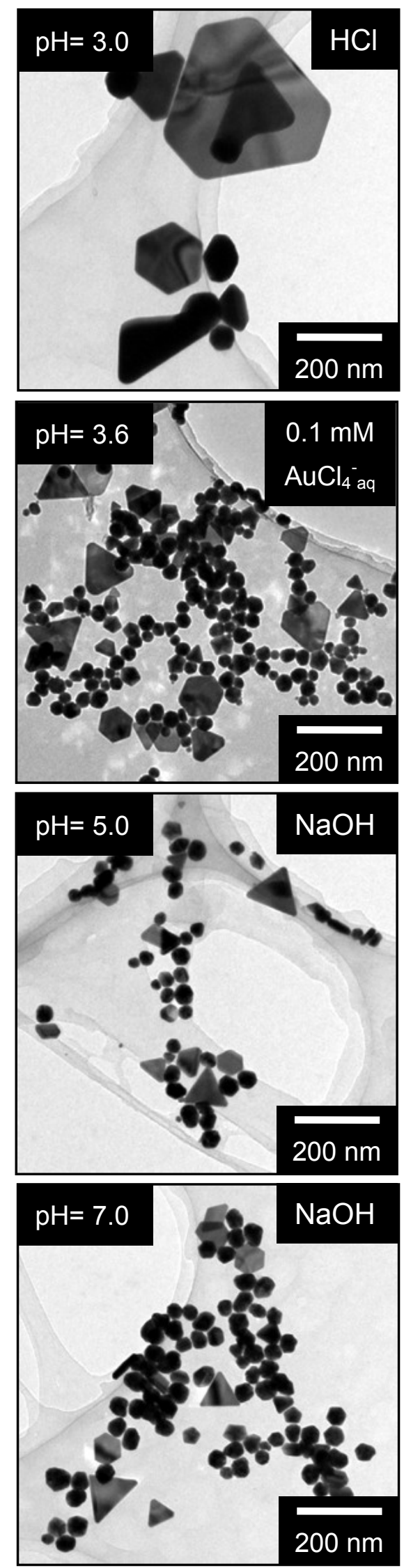
Figure 9. Sakai et al.
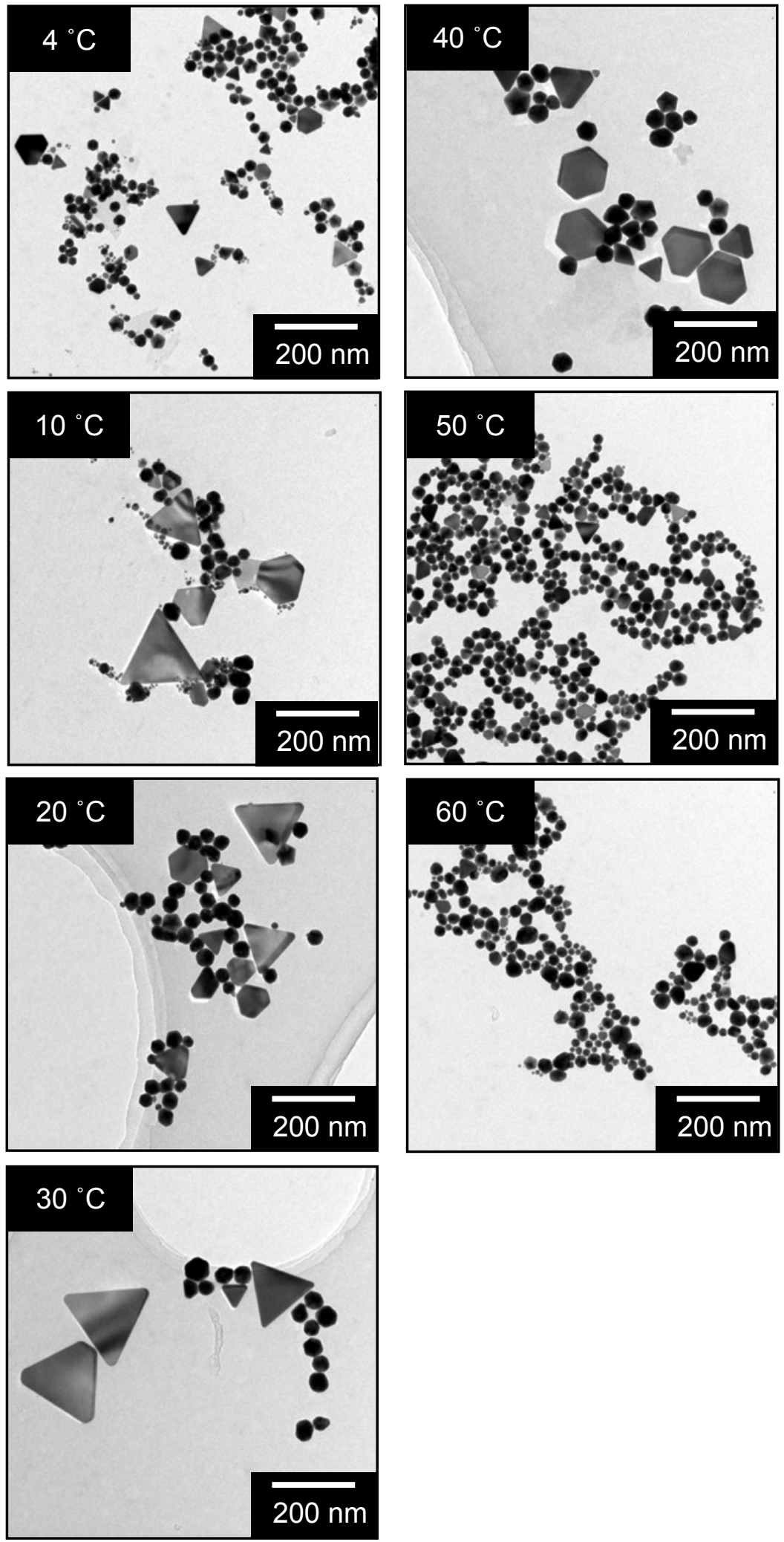
Figure 10. Sakai et al.
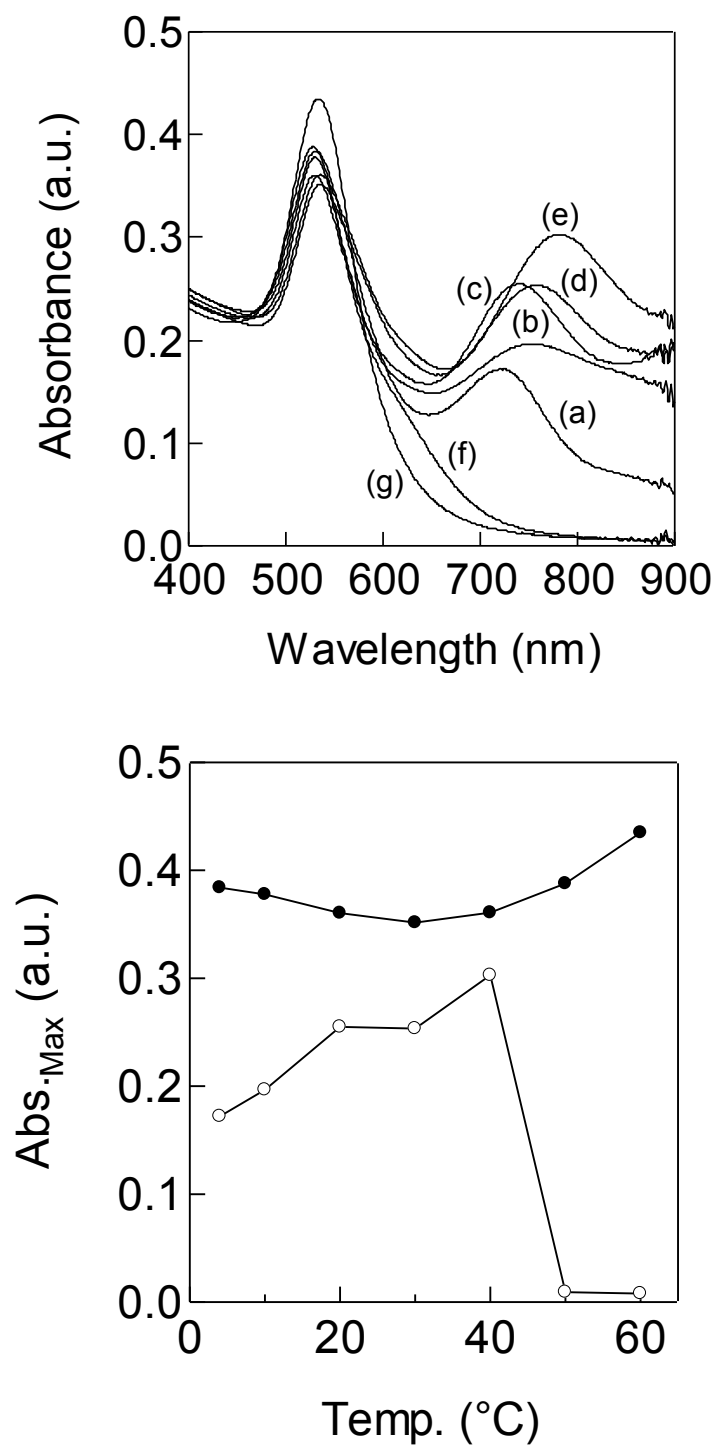